\title{
Laudatio for the 2009 Fåhraeus Awardee: Prof. Dr. Friedrich Jung
}

\author{
Mr Chairman, Ladies and Gentlemen,
}

It is a pleasure and great honour to have been asked to give the Laudatio to the 14th Fåhraeus Medallist, to an extremely worthy recipient and to a good friend: to Professor Friedrich Jung. The ceremony of presenting the Medal is one of the most pleasant and important events at any of our meetings, when we celebrate one of the great founders of our field, Robin Fåhraeus, and award the Medal named after him to a more recent outstanding worker in the field.

I shall, of course, return to Friedrich, but I should like to start by paying a short homage to Fåhraeus and the history of the Medal.

One of the things that interested Fåhraeus when he was a young clinician was the way blood settled if it was left to stand in a tube for a while. What initiated his interest was the observation that the rate of settling was high in pregnant women and got faster the later the pregnancy. He then noticed that in many pathologies the rate was much higher than in healthy individuals. He developed this into the Erythrocyte Sedimentation Rate Test, a non-specific index of pathology. It is be one of the simplest and longest surviving medical tests on record. These studies led him to a deep interest in the enigmatic phenomenon of red cell aggregation, which together with his interest in comparative blood flow ultimately led to his exquisite studies of the way blood flows in small bore tubes and the factors affecting it - results of enormous relevance to blood flow in the nutrient vessels in vivo.

These were major contributions, and in recognition he was celebrated by being the first awardee of the Poiseuille Medal by the International Society of Biorheology in 1966 at their meeting in Reykjavík. Sadly, just two years after receiving the Poiseuille Medal, Fåhraeus died.

Not long after the formation of the $\mathrm{ESCH}$, it decided to establish a Medal to celebrate outstanding workers in Clinical Haemorheology and inevitably it was called the Fåhraeus Medal. The first meeting of the ESCH was in 1979 in Nancy when no award was made - the Medal had not yet been invented! So the first award was made in 1981 at the London meeting and the awardee was Professor Shu Chien. He is shown - Fig. 1 - here standing in front of a painting of Fåhraeus himself.

Since then the Medal has been awarded to 14 people including the current one here at Pontesina. So let me introduce the 14th Winner of the Fåhraeus Medal - Professor Friedrich Jung (Fig. 2).

I have not known Professor Jung on a personal level for very. I have known of his work for much longer and there is no doubt that he is an outstanding Fåhraeus Medallist, having organised a great deal of rigorous research in many areas related, and unrelated, to haemorheology. I shall talk more about that later, but let me start with a short history of his professional career.

One aspect of Friedrich's history that makes him unique amongst the Fåhraeus Medallists is that he is an engineer by early training. This, I believe, has influenced his approach to haemorheological studies - 


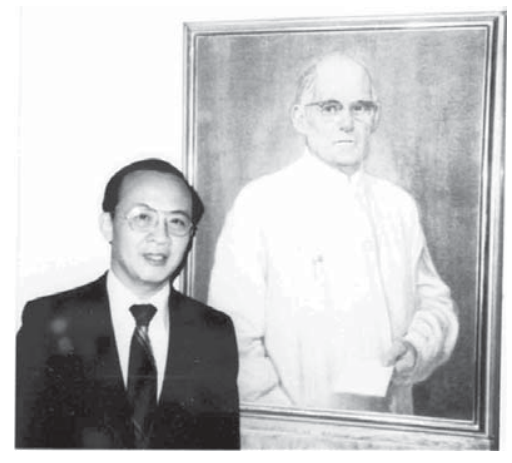

Fig. 1. The first Fåhraeus Medallist: Prof. Shu Chien.

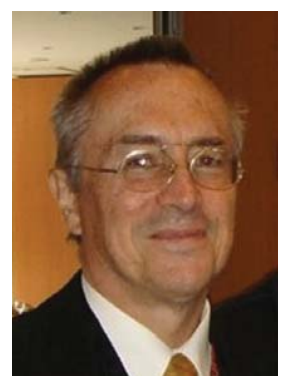

Fig. 2. Prof. Friedrich Jung.

which is particularly rigorous and wide ranging. So we start with his education. He first studied Nuclear Techniques, at Aachen. He followed this up by studying Physical Engineering Science, with special emphasis on Thermodynamics and Fluid Dynamics, at the Technical University West Berlin and stayed on there, in the Institute for Thermodynamics and Fluid Dynamics, for a couple of years after graduating. It was then that he made the profoundly important move, in 1981, to the Department of Physiology at RWTH Aachen, where he worked with Professors Holger Schmidt Schoenbein, Kiesewetter, Wolf etc. The die was cast - he had found his niche. But to complete the education story, in 1985 he was awarded his PhD in Physical Engineering and, in 1992, his Habilitation at the University of Saarland.

In 1983 he moved as a post graduate to the Department for Clinical Haemostasiology and Transfusion Medicine at the University of Saarland, but quickly rose to Senior Engineer and, finally, Head of Section of Failure Analysis and Quality Management. From there he became Director of the Institute of Heart and Circulation Research, first in Dresden and latterly in Hoyerswerda. In 2007, he became Project Coordinator for Clinical Applications for the Centre of Biomaterial Development, GKSS-Institute of Polymer Research, Teltow. More recently he has been made Head of the Department of Biointerface Engineering at the Berlin Brandenburg Centre for Regenerative Therapies and Temporary Head of the Department of Biocompatibility at Centre for Biomaterial Development, GKSS Institute of Polymer Research, Teltow.

This tells us that here we have a man who is extremely active, with great and multifaceted talent.

Now to his research; In the time available I can only scratch the surface. In the early days he was involved in the development of a number of hemorheological devices. Two examples are a capillary 
tube plasma viscometer and the Rigidometer for measuring RBC deformability. He was also involved in many basic haemorheological studies such as comprehensive investigations of the factors affecting plasma viscosity and yield stress. He was also involved in a number of clinical studies of, for example, diabetes.

However, early on he felt that haemorheological results were not enough, he had to try to relate these to in vivo flow. His early work in this direction involved measuring blood flow in the retina and conjunctiva of the eye. Later his interests expanded to haemostasis, especially abnormalities leading to thrombosis and thromboembolism, to platelet dysfunction and to dysfibrinogenaemia.

Through all of this he has had a deep interest in the effects of pharmaceutical intervention. Thus he has conducted a multitude of very rigorous controlled trials of pharmaceutical agents associated with diabetes, hypertension, polycythaemia, haemodilution etc.

He is not one to stand still and so his investigations have spread to include the measurement of tissue oxygen perfusion. Latterly he has a considerable bibliography on the effects of various contrast media on blood rheology, flow, tissue oxygen delivery and coagulation. But he has now spread much further into magnetocardiography for diagnostics in acute chest pain, of microwave ablation for atrial fibrillation treatment and the study of the effects of artificial materials in vivo on haemorheology, blood flow and coagulation. The breadth of his interests is remarkable.

He has produced in excess of 358 peer reviewed publications, over 200 book chapters and edited or coedited 14 books. As if this were not enough, he is an Editor-in-Chief of Clinical Hemorheology and of the Journal of Cardiopulmonary Pathophysiology and Founding Editor of the Journal of Magnetocardiology. $\mathrm{He}$ has been Vice President and then President of the ESCH and, of course, he organised the very successful European meeting in Dresden in 2007.

One wonders when he finds time to sleep.

So, Friedrich, I congratulate you on the award which you so richly deserve for your great contribution to research, I salute you for your great efforts in pushing our field forward, for your efforts with regard to our journals and for organising our meetings. I greatly appreciate being involved with a good friend and one of the nicest Medallists I have known.

I look forward to your lecture.

Mike Rampling

Imperial College

London 